\title{
Controle de Integridade e Administração Pública: Sinergias Necessárias
}

\author{
Integrity Control and Public Administration: Necessary Sinergies
}

\author{
Rogerio Gesta Leal ${ }^{1,2}$ \\ ${ }^{1}$ Universidade de Santa Cruz do Sul, RS, Brasil \\ ${ }^{2}$ Fundação Escola Superior do Ministério Público, Porto Alegre, RS, Brasil
}

\begin{abstract}
Resumo: O presente trabalho tem como objetivo verificar em que medida o controle de integridade, pensado a partir de modelos como o compliance, pode aprimorar os sistemas de controle interno da Administração Pública brasileira. O problema de pesquisa pretende apontar quais medidas podem ser adotadas para melhorar esses sistemas de controle. A hipótese é de que se faz necessária a adoção dos mecanismos de integridade como forma de qualificar os instrumentos de controle interno. Para isso, serão demarcados elementos conceituais da integridade na gestão, constituindo o compliance como espaço de qualificação do controle interno e da ação administrativa governativa.
\end{abstract}

Palavras-chave: Administração Pública. Controle da Administração. Compliance.

\begin{abstract}
The present work has the objective to verify how integrity control, structured in a model like compliance, can help to improve the systems of intern control of Brazilian public administration. The research problem focuses in responding what measures can be adopted to improve these control systems, and the hypothesis is that is necessary to use these integrity mechanisms in a way to qualify intern control instruments. For this, it will be delimiting some conceptual elements of integrity in public management, constituting compliance program as a space to qualify programs of intern control and government administrative action.
\end{abstract}

Keywords: Public Administration. Management Control. Compliance.

Recebido em: 13/04/2019

Revisado em: 15/10/2020

Aprovado em: 30/11/2020 


\section{Introdução}

A gestão pública em todo o mundo hoje tem suas configurações organizacionais e funcionais impactadas por multifacetados riscos advindos de modo inexorável das próprias relações sociais, marcadas que estão por hipercomplexidades econômicas, políticas, culturais e mesmo institucionais. Tais fenômenos apresentam desafios imensos, de um lado, políticas públicas são geradas para atender a tantas demandas consectárias desses cenários; por outra via, são os mecanismos de controle, a transparência, a prestação de contas e a responsabilização dos administradores públicos e mesmo privados -, haja vista os perigos oriundos de todos esses processos, muito especialmente os abusos de poder, os desvios de finalidade e a corrupção, tão recorrentes nos dias atuais.

Por conta disso, a legislação internacional e nacional vem procurando aprimorar as ferramentas de evitação e de persecução de ilícitos e imoralidades perpetradas tanto por agentes estatais como do mercado, dentre as quais o compliance, que pode ser tomado como espécie de controle interno da Administração Pública. O problema é que simples mutação normativa não tem o condão de solver problemas desta natureza, mas precisam ser acompanhados de mudanças culturais paradigmáticas e de outros dispositivos fomentadores do controle.

Este é o objeto do presente texto: verificar em que medida o controle de integridade, pensado a partir de modelos como o compliance, pode aprimorar os sistemas de controle interno da Administração Pública brasileira. Para tanto, serão demarcados, preambularmente, alguns elementos conceituais da integridade na gestão, a partir das condições que se tem de tratar sobre a importância do mapeamento dos riscos e dos perigos reincidentes para o gestor público, a fim de constituir programa de compliance como espaço de qualificação do controle interno e mesmo da ação administrativa governativa. 


\section{Conformação e Integridade: alguns conceitos demarcatórios}

Já houve oportunidade de dizer que a corrupção tem evidenciado ao longo do tempo faces multissetoriais e capacidade de expansão infinita na rede de relações sociais e institucionais, públicas e privadas, em todo o mundo, e, nos últimos tempos, tem ganhado maior notoriedade em face da difusão e da redifusão midiática tradicional (jornais, televisão, rádio) e alternativa (blogs, twiters, facebooks, redes sociais, etc.), não se extraindo daí, em regra, análises, diagnósticos e prognósticos mais aprofundados de suas causas e consequências (LEAL, 2013).

Ao lado dos aspectos positivos de progressiva amplitude do debate sobre o tema, conta-se hoje com mais leis, tratados, convenções, pactos, sentenças judiciais e procedimentos administrativos que se ocupam dessas questões, gerando até reflexos sobre a opinião pública de massa, que tem resgatado a capacidade de indignação quanto a isso, o que se afigura importante.

Desde a década de 1970, há no Ocidente preocupações mais formais com o tema, haja vista a edição do Foreign Corrupt Practices Act (FCPA), de 1977, nos EUA, e mesmo os tratados internacionais relacionados com o combate à corrupção de funcionários públicos estrangeiros, da Organização para a Cooperação e Desenvolvimento Econômico (OCDE), e documentos das Nações Unidas. Não bastassem tais documentos, pode-se contar com alguns instrumentos jurídicos internacionais decorrentes dessa preocupação, entre os quais: (a) o Código Internacional de Conduta para os titulares de cargos públicos, aprovado pela Resolução n. 51/59, da Assembleia Geral das Nações Unidas; (b) a Declaração das Nações Unidas contra a Corrupção e o Suborno nas transações comerciais internacionais, igualmente aprovada pela Resolução n. 51/59, da Assembleia Geral das Nações Unidas; (c) a Resolução n. 54/128, da Assembleia Geral, fazendo suas as conclusões e recomendações aprovadas pela Reunião do Grupo de Expertos sobre a Corrupção e seus Circuitos Financeiros, celebrada em Paris, nos dias 30 de março a $1^{\circ}$ de abril de 1999; (d) a Convenção Interamericana contra a Corrupção, aprovada pela Organização dos Estados Americanos em 29 de março de 1996; entre outros (KLITGAARD, 2005). 
Nesta década de 1990, é importante também fazer referência à iniciativa norte-americana de ampliar os mecanismos de enfrentamento da corrupção, criando suas US Sentencing Guidelines, promulgadas em 1991, aí sim fomentando em muito o instituto do compliance como possibilidade de incremento de políticas de integridade corporativa e eventual atenuante de responsabilidade jurídica pela prática de ilícitos federais. Os anos de 1990 foram a década em que a remuneração dos administradores se transmudou de um valor prioritariamente fixo para se basear nas ações. Com essa mudança, segundo Frazão e Medeiros (2019), a remuneração passou a ter como parâmetro a performance a curto prazo das ações. Essa mudança remuneratória, segundo os autores, transformou o valor das ações em uma preocupação diária dos administradores, muito mais do que o risco de ofertas hostis (FRAZÃO; MEDEIROS, 2019).

É no final da década de 1990 que a Comissão da União Europeia amplia o seu debate e preocupação com a corrupção, dando ensejo à criação do chamado Organismo Europeu de Luta Antifraude (OLAF), em 1999. Em seus relatos, a OLAF aponta vários campos sujeitos à corrupção na comunidade europeia, identificando autores e responsabilidades, o que tem auxiliado em muitas estratégias e em ações de prevenções a riscos e perigos corruptivos. Já em 2011, a Comissão adotou um pacote anticorrupção que criou o chamado Mecanismo de Informação Anticorrupção da EU, para a avaliação periódica dos esforços dos Estados-Membros na luta contra a corrupção. Esse mecanismo avalia os resultados alcançados, as falhas e as vulnerabilidades dos Estados-Membros nesse campo, com o intuito de gerar maior empenho político na aplicação da tolerância zero à corrupção, promovendo a coaprendizagem e facilitando a partilha de boas práticas.

A partir daqui, vários programas anticorrupção foram criados na EU, entre os quais destacam-se: (i) o Programa Hércules, que se dedica a combater a fraude, a corrupção e outras atividades ilegais lesivas das finanças da União Europeia, incluindo a luta contra o contrabando e a contrafação de cigarros; (ii) o Programa Péricles, que é destinado a proteger o espaço europeu da contrafação de moedas e de notas falsas; (iii) o Programa Pluto, que é um sistema de informação antifraude, utilizando ferramentas analíticas com base em projetos de domínio de informação, 
acelerando a identificação de irregularidades, constituindo plataforma de intercâmbio entre autoridades nacionais e estrangeiras.

E, no Brasil, o que se tem feito em relação a isso? Bastante e pouco ao mesmo tempo! Bastante, porque a produção e a publicidade de informações de fácil acesso sobre os fenômenos corruptivos que têm ocorrido (principalmente em face do jornalismo investigativo) aumentam cada vez mais, auxiliando os processos de aferição de responsabilidades jurídicas as mais diversas (penais, civis, administrativas, dentre outras). Por outro lado, os fenômenos corruptivos se sofisticam e estão mais complexos no que tange às suas constituições e operações, nomeadamente no âmbito do crime organizado (macro e micro), na lavagem de dinheiro, terrorismo, etc., estando, não raro, à frente das políticas públicas e privadas de seus enfrentamentos, e mesmo dos meios e técnicas de persecução jurídica.

Daí a importância do aprimoramento permanente dos instrumentos de controles preventivos e curativos à corrupção em todas as suas formas.

No campo da Administração Pública, esses mecanismos de controle (interno e externo) estão incorporados em ordenamentos jurídicos múltiplos, a começar pela Constituição Federal, no Brasil, conforme mostra a dicção do seu artigo 70, envolvendo a fiscalização contábil, financeira, orçamentária, operacional e patrimonial da União e das entidades da administração direta e indireta, quanto à legalidade, legitimidade, economicidade, aplicação de subvenções e renúncia de receitas. Tal obrigação se estende para os Estados e Municípios, assim como para as instituições públicas descentralizadas.

O mesmo texto constitucional, ao tratar da organização do Estado, no capítulo das atribuições dos Municípios (em seu artigo 31), estabelece que a fiscalização destes será exercida por seu Poder Legislativo - pela via do controle externo -, e pelo próprio Poder Executivo Municipal, por meio de seus sistemas de controle interno.

As Constituições dos Estados-Membros brasileiros, modo geral, exigem que a fiscalização contábil, financeira, orçamentária, operacional e patrimonial do Estado, e dos órgãos e entidades da administração direta e indireta, e de quaisquer entidades constituídas e mantidas pelo Estado, 
quanto à legalidade, legitimidade, moralidade, publicidade, eficiência, eficácia, economicidade, aplicação de subvenções e renúncia de receitas, deverá ser exercida pela Assembleia Legislativa, mediante controle externo, e pelo sistema de controle interno de cada um dos Poderes, observado o disposto nos artigos 70 a 75 da Constituição Federal.

Veja-se que em todas essas normas há referência expressa de que os poderes de Estado devem constituir sistema de controle interno! Mas o que vem a ser esse sistema? Há requisitos e/ou caracteres normativos mínimos que se exigem dele? Em termos históricos não se teve muitos parâmetros ou diretrizes pontuais para a constituição desse sistema de controle interno, deixando para cada órgão público o fazer a seu talante, daí decorrendo a ausência de matrizes paradigmáticas e de orientação para tal mister, o que autorizou, por muito tempo, o reconhecimento de qualquer iniciativa - por mais precária que fosse - como aceitável.

A verdade é que não se tem dado de forma muito eficaz o controle interno em nível nacional, estadual e municipal, ora em razão da inexistência de cultura de controle dos atos da administração pública, o que difere de se afirmar não existirem condições objetivas de se fazê-lo, haja vista os comandos jurídicos assinalados; ora em face de serem escassos os seus paradigmas de instituição e gestão, o que é observado por Fortini e Silveira (2014).

Se formos avaliar, num primeiro momento, o que significa o referido controle interno, é possível trazer a ideia de que se trata da criação, dentro da própria organização, de mecanismos visando a aumentar a probabilidade de que os objetivos e as metas estabelecidos sejam atingidos por meio de procedimentos e processos legítimos e democráticos (igualmente controlados). Tal conceito preliminar é complexo, eis que envolve tanto os deveres impostos por regras como por princípios jurídicos, tornando a tarefa de monitoramento e fiscalização permanente algo imprescindível à consecução dos referidos fins colimados pela ação pública.

A perspectiva de autocontrole implica preparação/articulação de elementos (humanos e materiais) da própria administração, adequando sua estrutura administrativa e preparando servidores capazes de darem conta da natureza diferenciada e pertinente às tarefas consectárias, daí 
porque é imperioso que se estabeleçam para tais fins planos de organização, métodos e medidas voltadas para salvaguardar os recursos da Administração Pública, garantir e verificar a exatidão e a veracidade das informações que esta possui, promover a eficiência na gestão das receitas e despesas próprias, fomentar a observância das políticas prescritas e alcançar o cumprimento das metas e objetivos programados, nomeadamente os constitucionais, por óbvio que levando em conta a natureza privilegiada dos interesses que lhe são afetos.

Agora, agrega-se ao cenário normativo nacional o instituto do compliance, que seguramente representa mais que mecanismo de controle de gestão de negócios privados em face da suas integridades e conformação aos sistemas e ordenamentos jurídicos vigentes, mas diz com planos axiológicos e deontológicos de comportamentos voltados a escopos que, para além de lícitos, se integram a planos exógenos de existência do próprio interesse privado lato sensu, como o referente à sustentabilidade social, ambiental, humanitária, institucional, política e econômica dos interesses e ações em jogo (CANDELORO, 2012).

Então, essa fusão de horizontes entre os campos jurídicos cogentes e os valorativos e éticos cria performances amplas de integração que se projetam em modelos preventivos (e também curativos) de ações danosas a eles - tanto para o espaço público como para o privado -, pois é sempre importante evitar que situações de ilicitudes e imoralidades se concretizem - assim como as consequências decorrentes delas, sempre provocadoras de danos, riscos e perigos, individuais e transindividuais (ROSSETTI; PITTA, 2017). E eis o núcleo do compliance como política ampla de prevenção de danos, riscos e perigos a direitos e garantias individuais e sociais, claro que também atentando para a dimensão reparatória daquelas lesões consumadas (SILVEIRA; SAAD-DINIZ, 2015).

A Instrução Normativa Conjunta n. 01/2016, do Ministério Público-Controladoria Geral da União (CGU), que dispõe sobre controles internos, gestão de riscos e governança no âmbito do poder executivo federal, avança nessa preocupação, na medida em que sugere à Administração Pública a adoção de conceitos e de práticas contemporâneas de Bom Governo e que estão hoje sendo aplicados também pela iniciativa privada, en- 
tre os quais: (a) governança, como combinação de processos e estruturas implantadas pela alta administração, para informar, dirigir, administrar e monitorar as atividades da organização, com o intuito de alcançar os seus objetivos; (b) governança no setor público, constituída por mecanismos de liderança, estratégia e controle postos em prática para avaliar, direcionar e monitorar a atuação da gestão, com vistas à condução de políticas públicas e à prestação de serviços de interesse da sociedade; (c) gerenciamento de riscos (e o controle interno aqui é de suma relevância), definido como processo para identificar, avaliar, administrar e controlar potenciais eventos ou situações, para fornecer razoável certeza quanto ao alcance dos objetivos da organização.

É a mesma CGU, aliás, que em seu Programa de Integridade: diretrizes para empresas privadas, define tal programa como o conjunto de medidas e de ações institucionais voltadas para a prevenção, detecção, punição e remediação de fraudes e atos de corrupção.

Da mesma forma, o Decreto Federal n. 8.420/2015, que regulamenta a Lei Anticorrupção (Lei n. 12.846/2013) no âmbito da União, define em seu artigo 41, o denominado Programa de Integridade, identificando-o como conjunto de mecanismos e procedimentos internos de integridade, auditoria e incentivo à denúncia de irregularidades e na aplicação efetiva de códigos de ética e de conduta, políticas e diretrizes com objetivo de detectar e sanar desvios, fraudes, irregularidades e atos ilícitos praticados contra a administração pública, nacional ou estrangeira.

É no artigo 42 deste Decreto que é possível encontrar um conjunto interessante de critérios aferitórios exemplificativos (porque outros poderão ser instituídos pela autoridade administrativa), mas vinculantes, da efetividade dos programas de compliance adotados pelas empresas visando a atenuante da sanção prevista na Lei n. 12.846/2013. Esses requisitos estabelecidos pela norma são suficientes para auxiliar na formatação de programas de integridade, desde que tenham ainda monitoramento qualitativo (virtuais e físicos, notadamente preventivos) da execução das ações, políticas e procedimentos ali referidos, de preferência em tempo real, sob pena de não se ter condições de mensurar a dimensão pragmática dos programas de integridade. 
Sob o ponto de vista das vantagens para além dos fatores da integridade e gestão proba que tais dispositivos enunciam, considerando eventuais penalizações das pessoas jurídicas decorrentes de condenação por atos de corrupção ou ilícitos praticados contra a Administração Pública, tem-se a possibilidade dos acordos de leniência (realizados pelas próprias autoridades administrativas), que podem isentar empresas das sanções previstas no inciso II, do artigo $6^{\circ}$, e no inciso IV, do artigo 19 , todos da Lei n. 12.846/2013, e ainda reduzir em até $2 / 3$ (dois terços) o valor da multa aplicável a elas, lembrando, todavia, que esse acordo não as eximem da obrigação de reparar integralmente o dano causado - conforme artigo 16, parágrafos $2^{\circ}$ e $3^{\circ}$, da mesma normativa.

Isso é tão importante que o compliance constituiu-se como exigência da Comissão de Valores Mobiliários (CVM) e do Banco Central do Brasil (BACEN) para determinadas pessoas jurídicas e relações negociais, além de ser exigido - com base na Lei das Estatais (Lei n. 13.303/2016) -, para as empresas públicas, sociedades de economia mista e subsidiárias. Na mesma direção, a Resolução n. 2.554/1998, do BACEN, determinou, às instituições financeiras, e àquelas autorizadas a funcionar por esse órgão, a implantação e a implementação de controles internos voltados para as atividades por elas desenvolvidas.

Já o Decreto Federal n. 9.203, publicado em 22 de novembro de 2017, determinou a instituição de programa de compliance no âmbito dos órgãos e entidades da administração pública federal direta, autárquica e fundacional. Nesse documento, já estão os escopos do programa para os fins de remediar fraudes e atos de corrupção, sendo estruturado em torno de quatro eixos: (i) comprometimento e apoio da alta administração; (ii) existência de unidade responsável pela implantação do programa; (iii) análise, avaliação e gestão de riscos associados à integridade; e (iv) monitoramento dos atributos do programa (artigo 19).

Foi no mesmo caminho a CGU ao criar o Manual para a Implementação de Programas de Integridade - orientações para o setor público, estabelecendo parâmetros sugestivos de conformidade a serem observados na instituição de programas de integridade no setor público. Esse documento deixa muito claro que: Promover uma cultura de integridade 
no serviço público é requisito essencial para o aumento da confiança da sociedade no Estado e em suas instituições. Manter um alto nível de integridade e desenvolver uma cultura organizacional baseada em elevados valores padrões de conduta, constitui política pública fundamental a ser constantemente promovida e incentivada pelos governantes e gestores.

O Conselho Administrativo de Defesa Econômica (CADE) também elaborou seu guia Programas de Compliance ao mercado, dando destaque, entre outros elementos, à importância dos benefícios que trazem no campo da prevenção de riscos, identificação antecipada de problemas, reconhecimento de ilicitudes, vantagens reputacionais, conscientização dos funcionários, redução de custos e contingências (CADE, 2016).

Convém que a organização analise os riscos de compliance, considerando as causas e as fontes de não cumprimento e a gravidade de suas consequências, bem como a probabilidade de que os não cumprimentos e as consequências associadas possam ocorrer. As consequências podem incluir, por exemplo, danos pessoais e ambientais, perda econômica, danos à sua reputação e responsabilidade civil e administrativa.

Como quer Domingos Farinho (2019), todas essas preocupações têm como escopo nuclear assegurar a alquimia de uma empresa que deve simultaneamente ser competitiva no mercado em que opera, dado o seu objeto social, e a realização de interesses públicos específicos, num quadro de subordinação ao poder democrático e não necessariamente orientado pelo mercado.

E aqui tem-se momento sensível à criação do programa de integridade: o adequado e eficiente mapeamento dos riscos e perigos que podem afetar a empresa em suas áreas de atuação, sendo que, para cada uma delas, e diante das suas particularidades identitárias nos ambientes de negócios, haverá modelos, instrumentos e procedimentos específicos. Passemos a tratar disso.

\section{Mapeamento de Riscos e Perigos na Formatação do Compliance}

O tema do mapeamento de riscos e perigos à Administração Pública no âmbito de suas ações de gestão cotidianas é importante para qualquer 
demanda que reclama políticas públicas no formato de ações legislativas e executivas em todas as esferas de governo, nomeadamente para evitar desvios de finalidade, abuso de poder, corrupção, entre outras patologias que têm assolado países desenvolvidos ou em desenvolvimento.

Em Portugal, por exemplo, a Lei n. 54/2008 criou o Conselho de Prevenção da Corrupção (CPC) junto ao Tribunal de Contas de Portugal, que vem desempenhando papel importante na formatação de políticas públicas, ações e estratégias operacionais de mapeamento de riscos e perigos da corrupção em diversos setores da atividade administrativa e econômica do Estado e do Mercado (CUNHA; SERRA; COSTA, 2019).

No documento chamado Prevenção da Corrupção na Gestão Pública - mapeamento de áreas e fatores de risco, o CPC apresentou uma série de dados muito interessantes no sentido de estruturação desse mapeamento, dados que podem servir para a construção de metodologias de abordagem e procedimento dessa natureza.

As áreas prioritárias que o CPC identificou, em 2018, como necessitadas de mapeamento de riscos e perigos de corrupção mais expostas foram: (1) contratação pública; (ii) administração púbica eletrônica; (iii) ordenamento do território, urbanismo e ambiente; (iv) desportos e apostas; (v) saúde e farmacêuticas; (vi) forças de fiscalização e de polícia, segurança e defesa; e (vii) sistemas político e judicial. Tais conclusões, num primeiro momento, foram extraídas de várias audições de peritos e técnicos dessas áreas com funções de controle e auditoria do setor técnico dos tribunais de contas.

É mais interessante ainda o detalhamento do estudo do CPC quanto às tipologias de fragilidades detectadas que possivelmente facilitaram ou deram causa preponderante - as ocorrências corruptivas.

Não há dúvidas de que os gargalos acima identificados em Portugal têm replicação direta em muitos outros países, em especial no Brasil, basta ver quantos crimes são julgados pelos tribunais envolvendo o disposto no artigo 313-A, do Código Penal, criminalizando as condutas de inserir ou facilitar, o funcionário autorizado, a inserção de dados falsos, alterar ou excluir indevidamente dados corretos nos sistemas informatizados ou 
bancos de dados da Administração Pública com o fim de obter vantagem indevida para si ou para outrem ou para causar dano, com pena de reclusão de dois a 12 anos. Essas ações geralmente estão associadas a interesses privados e são executados pela via da propina totalmente ilícita.

Da mesma forma, conflitos de interesses estão presentes diariamente nas relações econômicas entre pessoas físicas e jurídicas, públicas e privadas, a despeito da tentativa de controle estabelecida pela Lei n. 12.813/2013; os controles dos serviços públicos concedidos e delegados são pífios; o abuso e desvio de poder de muitas autoridades públicas tem dado vezo à corrupção; a malversação do patrimônio e do dinheiro públicos da mesma forma chega a ser banalizada na política brasileira, configurando verdadeira privatização por parte de muitos agentes privados e estatais; os modelos de controles internos e externos dos processos de execução de contratos públicos (onde se encontram os maiores riscos e perigos de corrupção) afiguram-se como demasiadamente deficitários (MUÑOZ; LEAL, 2016).

Seguramente, se tivéssemos estudos dessa natureza, como os desenvolvidos pelo CPC com tamanha profundidade (não se desconsideram os esforços alocados pelos Tribunais de Contas dos Estados e da União, assim como da Controladoria Geral da União), seria possível constituir mapas de riscos que poderiam gerar políticas públicas preventivas mais eficientes.

E no seu documento Programa de Integridade, a CGU alinha que a estruturação de Programa de Integridade depende também da avaliação de riscos que leve em conta: as características dos mercados em que a empresa atua (cultura local, nível de regulação estatal, histórico de corrupção). Essa avaliação deve considerar principalmente a probabilidade de ocorrência de fraudes e corrupção, inclusive ligadas a licitações e contratos, e o impacto desses atos lesivos nas operações da empresa (CONTROLADORIA GERAL DA UNIÃO, 2017).

Simonsen (2019) lembra que inúmeras atividades empresariais têm evidenciado potencialidades de riscos e perigos no cometimento de ilícitos passiveis de evitação e responsabilidade pela via do compliance, entre as quais: participação em licitações, licenciamentos ambientais, fusões, 
aquisições e reestruturações empresariais, fixação de preços, manipulação de demonstrativos contábeis e financeiros, obtenção de registros, permissões, licenças administrativas, oferecimento e recebimento de patrocínio ou doações, elaboração de revisão de contratos de obras e serviços, dentre outros. Em seguida, o autor agrega ao seu argumento algumas causas conhecidas e recorrentes que levam àquelas situações de riscos e perigos, a saber: projetos mal especificados e sem a devida análise de viabilidade técnica e financeira, ou sem objeto bem definido; contratos assumidos sem capacidade orçamentária; falta de capacidade de fiscalização especializada; alocação ineficiente de riscos; atraso no cumprimento das obrigações contratuais pelo setor público e privado (SIMONSEN, 2019).

Frazão e Medeiros (2019) sugerem que o mapeamento de riscos passe, entre outros momentos, por: (i) entrevistas com empregados de diferentes áreas da empresa (comercial, marketing, jurídico, RH); (ii) análise de documentos atinentes à sua área de atuação e a de seus parceiros econômicos; (iii) análise dos contratos com a Administração Pública, detalhando o grau de interação com o Poder Público; (iv) análise dos potenciais impactos que a atividade econômica pode causar ao meio ambiente e aos consumidores e de seus mecanismos de prevenção e responsabilidade quanto a isso.

É certo que para tais momentos e ações se realizarem importa já estarem constituídas estruturas e atitudes adequadas para suas efetivações, entre as quais: (i) a decisão das autoridades competentes para fazê-lo; (ii) a formatação de grupos de trabalhos às tarefas e os responsáveis e interlocutores das áreas eleitas; (iii) a definição de competências entres os atores envolvidos; (iv) a delimitação dialógica, a partir de fundados critérios predefinidos, dos casos-paradigmas de quebra de integridade inicialmente trabalhados, e de seus diagnósticos preliminares detalhados; (v) a formação dos planos personalizados de trabalho com metas, ações, prazos, mecanismos - físicos e virtuais - de monitoramento e avaliação transparentes e, preferencialmente, em tempo real; e (vi) a prestação de contas dos programas de integridade, com detalhamento dos seus métodos, resultados, consequências e responsabilidades. 
Aqueles casos-paradigmas de quebra de integridade que devem também fundar o programa compliance são elementos indispensáveis no mapeamento dos riscos a que se submete a Administração Pública cotidianamente, principalmente os que se apresentam de forma iterativa nas glosas e controle externos dos Tribunais de Contas, facilmente identificados inclusive nos sites desses órgãos. Nesse ponto, a CGU faz referência expressa à importância dos dados e informações que já existem institucionalizados, como: relatórios de auditorias e investigações internas e externas, relatórios de fiscalização e medidas recomendadas às organizações por autoridades supervisoras, decisões judiciais contra atos da organização ou sobre sua área de atuação, medidas disciplinares tomadas contra agentes da organização, relatórios de incidentes, registros de reclamações e denúncias contra a organização ou seus agentes, reportagens e notícias das mídias.

Outro elemento importante aqui é o do constante aprimoramento das políticas de prevenção, com permanentes avaliações dos procedimentos adotados e seus resultados, eis que fenômenos corruptivos e de quebra da integridade inovam a todo tempo estratégias predatórias dos interesses públicos indisponíveis.

É importante lembrar que a Lei das Estatais já referida avançou bastante nesses temas, impondo requisitos de transparência bem objetivos em seu artigo $8^{\circ}$, entre os quais o da divulgação tempestiva e atualizada de informações, entre outras, (i) relativas às atividades desenvolvidas; (ii) estruturas de controle; (iii) fatores de risco; e (iv) políticas e práticas de governança corporativa, gerando ampla divulgação, ao público em geral - veiculada na internet permanentemente - de carta anual de governança corporativa, que consolide em único documento escrito, em linguagem clara e direta, essas informações, consoantes aos incisos III e VIII e ao parágrafo $4^{\circ}$ desta Lei.

Esse Código de Conduta e Integridade, nos termos em que postos na Lei, ganha importância nuclear para os efeitos de controle interno e políticas de evitação e responsabilização de atos ímprobos, corruptos e fraudulentos, exigindo a implementação de ferramentas adequadas para tal mister, como (i) os canais de denúncias internas e externas (controle social), pro- 
tegendo quem as fizer; (ii) sanções por comportamentos violadores; e (iii) formação e treinamento pró-integridade e de gestão de riscos para todos os envolvidos na cadeia produtiva ou de serviços do órgão estatal.

Mas que tipo de treinamento deve ser exigido em face da integridade que a legislação exige? A ISO 19600 trata da matéria, dispondo sobre os caracteres dessa formação, a saber, entre outros: (i) que seja adaptado às obrigações e aos riscos de compliance relacionados com as funções e as responsabilidades dos funcionários, levando em conta inclusive as lacunas no conhecimento e na competência deles; (ii) que seja prático e facilmente compreendido pelos funcionários; (iii) que seja avaliado quanto à eficácia e atualizado permanentemente.

No tópico especial da gestão de riscos, a Lei das Estatais inova ao criar figura contratual de contorno conceitual aberto e, no caso, difícil de ser aquilatada, chamada matriz de riscos, ora definida como cláusula contratual definidora de riscos e responsabilidades entre as partes e caracterizadora do equilíbrio econômico-financeiro inicial do contrato, em termos de ônus financeiro decorrente de eventos supervenientes à contratação. Entre outras informações que essa cláusula contratual deve conter, destacam-se a listagem de possíveis eventos supervenientes à assinatura do contrato, impactantes no equilíbrio econômico-financeiro da avença, e a previsão de eventual necessidade de prolação de termo aditivo quando de sua ocorrência, disposta na alínea a, do inciso X, sob comento.

Cumpre dizer que já a Lei Federal n. 12.462/2011, que instituiu o Regime Diferenciado de Contratações Públicas, e admite o regime de Contratação Integrada (RDCi), ainda que de forma mais facultativa, em seu artigo $9^{\circ}, \S 5^{\circ}$, estabelecia que: se o anteprojeto contemplar matriz de alocação de riscos entre a administração pública e o contratado, o valor estimado da contratação poderá considerar taxa de risco compatível com o objeto da licitação e as contingências atribuídas ao contratado, de acordo com metodologia predefinida pela entidade contratante. Ou seja, não se pode falar de ineditismo total dessas possibilidades de ampliação do controle da Administração Pública trazidas pela Lei das Estatais, mas sim aprimoramento e vinculatividade maiores. 
Diante desses elementos, é possível dizer que configuram etapas do gerenciamento de riscos e formatação da sua matriz contratual: (i) o planejamento da meta pública com a clara identificação de seu objeto detalhado; (ii) as análises fundadas dos fatores econômicos/orçamentários, técnicos, sociais e formais necessários ao desiderato; (iii) as condições e possibilidades jurídicas dos seus termos; (iv) as ações públicas, seus prazos e condições de exequibilidade para a persecução do objeto pretendido; (v) o monitoramento institucional, em tempo real e de forma transparente (com prestação de contas), de todas essas fases do gerenciamento de riscos; (vi) os controles sociais dos riscos por meio de amplos mecanismos informativos, em tempo real, e eficientes, sob o ponto de vista da cognição e compreensão comunitária desses elementos, com canais de denúncias os mais democráticos possíveis; e (vii) a formatação de protocolos para respostas imediatas de evitação, responsabilização e reparação dos riscos potenciais e consolidados.

De qualquer sorte, o que importa é estar o mapa de riscos adequado em face da demanda pública existente, e que suas informações sejam suficientes e confiáveis para evitar danos e prejuízos, tanto ao interesse público indisponível envolvido como aos interesses privados das empresas e fornecedores da Administração, o que deverá ser associado a cada objeto contratado, inexistindo fórmula universal para tanto.

O Estado do Rio Grande do Sul sancionou a Lei n. 15.228, de 25 de setembro de 2018, que dispõe sobre a aplicação, no âmbito da Administração Pública Estadual, da Lei Brasileira Anticorrupção (Lei n. 12.846/2013), que exige, em seu artigo 37, um programa de integridade para as empresas que celebrarem contrato, consórcio, convênio, concessão ou parceria público-privada com a Administração Pública Estadual, a partir de determinados valores.

\section{Conclusão}

A despeito da importância do compliance para a Administração Pública em prol da integridade, é preciso reconhecer que há riscos também que podem comprometê-lo, e um dos mais reiterados tem a ver com aque- 
les programas que já nascem, deliberadamente, de modo a não funcionar ou cumprir com seus escopos matriciais, pois criam ambientes falsos de conformidade e, em verdade, servem para tentar mascarar ações ilícitas e antiéticas dos seus instituintes. Nesse ponto, vale a advertência de Emerson Gabardo e Gabriel Castella (2015, p. 142):

Nesse contexto, ressalta-se a importância dos órgãos responsáveis pela regulação dos programas de compliance, de modo a possibilitar a orientação das condutas e comportamentos das empresas interessadas em se relacionar com a Administração Pública. Afinal, tais empresas terão que, cada vez mais, aplicar dentro de si uma "ética de caráter público". Ou, no mínimo, terão que ter uma ética privada praticada "em público". O que denota também uma nova forma de incidência do princípio da publicidade. Não basta ter um programa de integridade, é preciso "mostrar que tem" - e o quanto funciona (ou seja, volta-se à eficiência). Este é um sistema que ultrapassa de forma significativa a ideia liberal de gestão empresarial. A teoria geral da infração administrativa cada vez mais está influenciando a prática interna das empresas, misturando as espécies de ilícitos a partir de um regime constitucional único.

Daí porque a necessidade imperiosa de existirem critérios claros de identificação dos elementos constitutivos necessários para que o compliance cumpra suas funções. Se não for assim, o que se terá são modelos de compliance para inglês ver, sem preocupações substanciais com ambientes de negócios íntegros e probos - públicos e privados, como ocorre com a constituição de compliances para simular migração de responsabilidades dentro da Administração Pública, utilizando indevidamente, entre outras, a figura do compliance officer, atribuindo a ele funções imensas de evitação do cometimento de ilícitos relacionados com os fins públicos por parte de seus servidores, sem, ao mesmo tempo, criar condições materiais, normativas, culturais e procedimentais para tanto.

Também existe o risco de que os programas de compliance criem situações, por causa de seus procedimentos e práticas de monitoramento das atividades de órgãos e de servidores, invasivas da intimidade e da privacidade de pessoas físicas e jurídicas, oportunidade em que se terá de 
equalizar os interesses público e privado envolvidos, o que nem sempre é tarefa fácil.

De qualquer sorte, os conjuntos de medidas aqui enfrentadas dizem respeito às práticas que têm por finalidade otimizar o desempenho do Estado na gestão do interesse público e, ao mesmo tempo, proteger todas as partes envolvidas com transparência e equidade, é como nos diz Coelho (2016).

Em apertada síntese, é possível afirmar que Governança no Setor Público diz respeito a um conjunto de mecanismos práticos de controle que envolvem temas afetos à liderança, estratégia e à informação com o objetivo de executar as quatro etapas: a) Identificar as questões sensíveis; b) Tratar os dados (informações) obtidos; c) Redimensionar o sistema corrigindo as falhas e implementando os modelos pendentes; d) Monitoramento periódico.

É necessário que se tenha claro, em face do todo expendido, que o controle interno exigido da Administração Pública pela Constituição brasileira não se restringe à adoção de ferramentas de integridade por parte dos órgãos públicos, mas estes configuram espécies de controle recomendados nomeadamente à prevenção de ilícitos que possam ser cometidos. Tanto é verdade isso que há municípios brasileiros que constituem seus sistemas locais de controle interno a partir de várias instâncias e espaços integrados, envolvendo de modo orgânico os departamentos de corregedoria-geral, ouvidora-geral, coordenações de auditorias internas e de promoção de integridade, acesso à informação.

Ou seja, o que importa é que existam políticas e ferramentas de controle interno e de integridade operando em sincronia e em direção uniforme, a partir justamente das diretrizes e dos objetivos constitucionais e infraconstitucionais estabelecidos, aperfeiçoando os processos e os procedimentos de transparência e de responsabilidade dos atos de gestão. 


\section{Referências}

ASSOCIAÇÃO BRASILEIRA DE NORMAS TÉCNICAS. ISO 19600. Sistemas de Gestão de Compliance: Diretrizes. Rio de Janeiro: NBR, 2014.

BRASIL. Decreto n. 6.021, de 22 de janeiro de 2007. Cria a Comissão Interministerial de Governança Corporativa e de Administração de Participações Societárias da União - CGPAR, e dá outras providências. Diário Oficial [da] República Federativa do Brasil, Brasília, DF, 22 de janeiro de 2007.

CADE. Guia Programas de compliance. 2016. Disponível em: http:// www.cade.gov.br/acesso-a-informacao/publicacoes-institucionais/guias do_Cade/guia-compliance-versao-oficial.pdf. Acesso em: 14 jan. 2020.

CANDELORO, Ana Paula P.; RIZZO, Maria B. M. de; PINHO, Vinícius. Compliance $360^{\circ}$ : riscos, estratégias, conflitos e vaidades no mundo corporativo. São Paulo: Trevisan Editora Universitária, 2012.

COELHO, Cláudio Carneiro Bezerra Pinto. Compliance na Administração Pública: uma necessidade para o Brasil. Revista de Direito da Faculdade Guanambi, [s.l.], v. 3, n. 1, julho-dezembro, 2016.

COMISSÃO DE VALORES MOBILIÁRIOS. Recomendações da CVM sobre governança corporativa. 2002. Disponível em: http://www.cvm. gov.br/decisoes/2002/20020529_R1/20020529_D07.html. Acesso em: 10 mar. 2020.

COMISSÃO EUROPEIA. Comunicação da comissão ao parlamento europeu e ao conselho. [2020a]. Disponível em: https://eur-lex.europa. eu/legal-content/PT/TXT/PDF/?uri=CELEX:52011DC0790\&from=EN. Acesso em 04 fev. 2020.

COMISSÃO EUROPEIA. A luta da União Europeia contra a fraude e a corrupção. [2020c]. Disponível em: https://www.compete2020.gov.pt/ admin/fileman/Uploads/publicacoes/Provisorios/A\%20Luta\%20da\%20 União\%20Europeia\%20contra\%20a\%20Fraude $\% 20 \mathrm{e} \% 20$ Corrupção.pdf. Acesso em: 4 fev. 2020. 
CONSELHO DE PREVENÇÃO DA CORRUPÇÃO. Prevenção da corrupção na gestão pública mapeamento de áreas e fatores de risco. 2018. Disponível em: http:/www.cpc.tcontas.pt/documentos/outros/ relatorio_mapeamento_riscos_2018.pdf. Acesso em: 4 fev. 2020.

CONTROLADORIA GERAL DA UNIÃO. Manual para implementação de programas de integridade. 2017. Disponível em: https://www.gov.br/cgu/pt-br/centrais-de-conteudo/publicacoes/etica-eintegridade/arquivos/manual_profip.pdf/view. Acesso em: 3 mar. 2020.

CONTROLADORIA GERAL DA UNIÃO. Metodologia de Gestão de Riscos. [2018]. Disponível em: https://www.gov.br/cgu/pt-br/centrais-deconteudo/publicacoes/institucionais/arquivos/cgu-metodologia-gestaoriscos-2018.pdf. Acesso em: 3 mar. 2020.

CONTROLADORIA GERAL DA UNIÃO; MINISTÉRIO PÚBLICO FEDERAL. Instrução normativa conjunta n. 1, de 10 de maio de 2016. Disponível em: http://www.in.gov.br/materia/-/asset_publisher/ Kujrw0TZC2Mb/content/id/21519355/do1-2016-05-11-instrucaonormativa-conjunta-n-1-de-10-de-maio-de-2016-21519197. Acesso em: 3 mar. 2020.

CONTROLADORIA GERAL DA UNIÃO. Programas de integridade: diretrizes para empresas privadas. [2020b]. Disponível em: https:// www.cgu.gov.br/Publicacoes/etica-e-integridade/arquivos/programa-deintegridade-diretrizes-para-empresas-privadas.pdf. Acesso em: 4 fev. 2020.

CUNHA, Ricardo A. S. da; SERRA, Sara A. E.; COSTA, Maria M. O. Medidas de combate à corrupção em Portugal. [2019]. Disponível em: https://pdfs.semanticscholar.org/0c6f/349d6f85ad9d161569624e0e96abae cd5770.pdf. Acesso em: 4 fev. 2020.

FARINHO, Domingos Soares. Programas de Integridade e governança das empresas estatais: uma visão portuguesa no contexto da União Europeia. In: CUEVA, Ricardo Villas Bôas e FRAZÃO, Ana (coord.). Compliance: perspectivas e desafios dos programas de conformidade. Belo Horizonte: Fórum, 2018. p. 233-249. 
FORTINI, Cristiana; SILVEIRA, Raquel Dias da. Perspectiva constitucional do controle interno. In: FORTINI, Cristiana; IVANEGA, Miriam Mabel (coord.). Mecanismos de controle interno e sua matriz constitucional: um diálogo entre Brasil e Argentina. Belo Horizonte: Fórum, 2014. p. 118-140..

FRAZÃO, Ana. (org.). Compliance: perspectivas e desafios dos programas de conformidade. Belo Horizonte: Fórum, 2019. p. 72-89.

FRAZÃO, Ana (org.). Constituição, Empresa e Mercado. Brasília, DF: UNB, 2017.

FRAZÃO, Ana; MEDEIROS, Ana Rafaela Martinez. Desafios para a efetividade dos programas de compliance. In: CUEVA, Ricardo Villas Bôas; FRAZÃO, Ana. (org.). Compliance: perspectivas e desafios dos programas de conformidade. Belo Horizonte: Fórum, 2019. p. 71-104. GABARDO, Emerson; CASTELLA, Gabriel Morettini. A nova lei anticorrupção e a importância do compliance para as empresas que se relacionam com a Administração Pública. A\&C - Revista de Direito Administrativo \& Constitucional, [s.l.], Ano 3, n. 11, jan.-mar. 2015. KLITGAARD, Robert. Controlling Corruption. Berkeley: University of California Press, 2005.

LEAL, Rogerio Gesta. Crimes contra a Administração Pública e a necessidade de um direito penal e processual penal subsidiário responsivo versus direito fundamental a privacidade e intimidade. In: LEAL, Rogerio Gesta; BITENCOURT, Caroline M. Temas Polêmicos da Jurisdição do Tribunal de Justiça do Rio Grande do Sul. Porto Alegre: TJRS, 2019. p. 141-167.

LEAL, Rogério Gesta; RECH, Caroline Andressa. Delimitação da postura do Tribunal de Contas do Estado do Rio Grande do Sul frente às irregularidades apontadas: análise acerca da coercibilidade das suas decisões e a capacidade de indução de boas práticas de gestão. In: LEAL, Rogerio Gesta; BITENCOURT, Caroline M. Temas Polêmicos da Jurisdição do Tribunal de Justiça do Rio Grande do Sul. Porto Alegre: TJRS, 2019. p. 89-119. 


\section{LEAL, Rogerio Gesta. Patologias Corruptivas nas relações entre}

Estado, Administração Pública e Sociedade: causas, consequências e tratamentos. Santa Cruz do Sul: Edunisc, 2013.

MUÑOZ, Jaime Rodríguez-Arana; LEAL, Rogerio Gesta. La respuesta jurídica a la corrupción en la contratación pública en Brasil y

España. Navarra: Editorial Aranzadi, 2016.

ROSSETTI, Maristela Abla; PITTA, Andre Gruspun (org.). Governança Corporativa: avanços e retrocessos. São Paulo: Quartier Latin, 2017.

SILVEIRA, Renato de Mello Jorge; SAAD-DINIZ, Eduardo.

Compliance, Direito Penal e Lei Anticorrupção. São Paulo: Saraiva, 2015.

SIMONSEN, Ricardo. Os requisitos de um bom programa de compliance. In: CUEVA, Ricardo Villas Bôas; FRAZÃO, Ana. (org.). Compliance: perspectivas e desafios dos programas de conformidade. Belo Horizonte: Fórum, 2019. p. 38-52.

Rogerio Gesta Leal é desembargador do Tribunal de Justiça do Estado do Rio Grande do Sul, lotado na Quarta Câmara Criminal com competência exclusiva para o julgamento de crimes contra a Administração Pública e de crimes praticados por Prefeitos e Vereadores. Professor Doutor e Titular da Universidade de Santa Cruz do Sul e da Fundação Escola Superior do Ministério Público (FMP), graduação, mestrado e doutorado.

E-mail: gestaleal@gmail.com

Endereço profissional; Rua 28 de Setembro, n. 202, apto. 1.402, Santa Cruz do Sul, RS, Brasil. CEP: 96812-040.

ORCID: https://orcid.org/0000-0003-1372-6348 